\title{
Genome-wide detection of natural selection in African Americans pre- and post-admixture
}

\author{
Wenfei Jin, ${ }^{1}$ Shuhua Xu, ${ }^{1,6}$ Haifeng Wang, ${ }^{2}$ Yongguo $\mathrm{Yu},{ }^{3}$ Yiping Shen, ${ }^{4,5}$ Bailin $\mathrm{Wu},{ }^{4,5}$ \\ and Li Jin ${ }^{1,4,6}$ \\ ${ }^{1}$ Chinese Academy of Sciences Key Laboratory of Computational Biology, Chinese Academy of Sciences and Max Planck Society \\ (CAS-MPG) Partner Institute for Computational Biology, Shanghai Institutes for Biological Sciences, Chinese Academy of Sciences, \\ Shanghai 200031, China; ${ }^{2}$ Chinese National Human Genome Center, Shanghai 201203, China; ${ }^{3}$ Shanghai Children's Medical \\ Center, Shanghai Jiaotong University School of Medicine, Shanghai 200127, China; ${ }^{4}$ Ministry of Education (MOE) Key Laboratory of \\ Contemporary Anthropology, School of Life Sciences and Institutes of Biomedical Sciences, Fudan University, Shanghai 200433, China; \\ ${ }^{5}$ Children's Hospital Boston, Harvard Medical School, Boston, Massachusetts 02115, USA
}

\begin{abstract}
It is particularly meaningful to investigate natural selection in African Americans (AfA) due to the high mortality their African ancestry has experienced in history. In this study, we examined 491,526 autosomal single nucleotide polymorphisms (SNPs) genotyped in 5210 individuals and conducted a genome-wide search for selection signals in 1890 AfA. Several genomic regions showing an excess of African or European ancestry, which were considered the footprints of selection since population admixture, were detected based on a commonly used approach. However, we also developed a new strategy to detect natural selection both pre- and post-admixture by reconstructing an ancestral African population (AAF) from inferred African components of ancestry in AfA and comparing it with indigenous African populations (IAF). Interestingly, many selection-candidate genes identified by the new approach were associated with AfA-specific highrisk diseases such as prostate cancer and hypertension, suggesting an important role these disease-related genes might have played in adapting to a new environment. CD36 and $H B B$, whose mutations confer a degree of protection against malaria, were also located in the highly differentiated regions between AAF and IAF. Further analysis showed that the frequencies of alleles protecting against malaria in AAF were lower than those in IAF, which is consistent with the relaxed selection pressure of malaria in the New World. There is no overlap between the top candidate genes detected by the two approaches, indicating the different environmental pressures AfA experienced pre- and post-population admixture. We suggest that the new approach is reasonably powerful and can also be applied to other admixed populations such as Latinos and Uyghurs.
\end{abstract}

[Supplemental material is available for this article.]

\begin{abstract}
Although the vast majority of human genetic variations evolve neutrally, some parts, however, have been shaped by natural selection (Kimura 2003; Balaresque et al. 2007). Studies on recent natural selection have led to the discovery of genes showing population differences in adapting to pathogens, diet, climate, and other environmental challenges. These discoveries have greatly enriched our understanding about the origins and also the evolutionary history of the human species, identified many genes with important biological functions, and will lead to further elucidation of the genetic basis of some human diseases (Balaresque et al. 2007; Nielsen et al. 2007; Sabeti et al. 2007; Hancock et al. 2008; Akey 2009). The recent availability of high-density SNPs has provided essential resources for genome-wide detection of natural selection, especially in ethnically well-defined populations with little admixture (Sabeti et al. 2007; Barreiro et al. 2008; Akey 2009). Although there have been several studies on recently admixed populations (Tang et al. 2007; Basu et al. 2008; Bryc et al. 2010), no study so far has particularly investigated the locus-specific population differentiation between the ancestral components of an admixed population and its ancestral parental population, which
\end{abstract}

\footnotetext{
${ }^{6}$ Corresponding authors.

E-mail xushua@picb.ac.cn.

E-mail lijin.fudan@gmail.com.

Article published online before print. Article, supplemental material, and publi-
} cation date are at http://www.genome.org/cgi/doi/10.1101/gr.124784.111. might reflect the natural selection since the two split. In this case, we used African Americans, a well-studied admixed population, as the object of our study.

African Americans (AfA) are residents of the United States with partial recent Sub-Saharan African ancestry. The majority of them are descendents of the Africans, probably 500,000 to 650,000 in number, who were forcibly brought to North America during the Middle Passage (Thomas 1999; Zakharia et al. 2009). However, many of those captive Africans died either during the Atlantic shipment to America due to the severe conditions, or soon upon their arrival in the New World as a result of exposure to foreign pathogens and/or the poor living conditions. Although the exact amount of life lost in this process remains a mystery, it may equal or exceed the actual amount enslaved (Stannard 1993). Therefore, the high mortality of AfA in the whole slavery era could be attributed to the overwhelming environmental challenges. These persistent selection pressures might make the frequencies of "beneficial" alleles increase continually, which should lead to higher population differentiation between African components of ancestry in AfA and indigenous Africans at these loci, in contrast to those evolved neutrally.

Meanwhile, before Africans and Europeans migrated to the New World, their ancestral parental populations had evolved independently in distinct environments for tens of thousands of years (Basu et al. 2008). The completely new environment in the New World constituted a challenge for both populations and the populations of their admixture. Therefore, it is very likely that 
some genomic regions in AfA show an excess of a particular ancestry as a result of selection pressures after the population admixture (Tang et al. 2007; Basu et al. 2008). For example, there are various studies in detecting signatures of selection in AfA by examining admixture proportion using a small number of available loci (Workman et al. 1963; Reed 1969; Blumberg and Hesser 1971; Adams and Ward 1973; Long 1991). Recently, Bryc et al. (2010) identified three autosomal regions showing excessive or reduced African ancestry (by at least three standard deviations [SD] of the mean) as natural selection candidates based on $\sim 500 \mathrm{~K}$ SNPs genotyped in 365 AfA.

Here, we analyzed the genotype data from $\sim 500,000$ autosomal SNPs shared by 1890 AfA and 3320 non-AfA for detecting the signatures of selection in AfA that were classified into preadmixture and post-admixture according to the different environments they experienced (Supplemental Fig. S1). Firstly, we detected the natural selections that were more likely to occur after admixture by examining the genome-wide distribution of ancestry in AfA. Then we developed a new strategy by reconstructing an ancestral African population (AAF) from inferred African components of ancestry in AfA and comparing it with indigenous African populations (IAF) (Supplemental Fig. S2), which reflect natural selection since the African ancestors of AfA left Africa (including both pre- and post-admixture). Many candidate genes identified by our new approach could explain the challenges that AfA and their ancestry had experienced. Thus we suggest that our new approach is reasonably powerful and can also be applied to the studies of other admixed populations.

\section{Results}

\section{African and European ancestries in AfA}

The populations from West Africa and Europe, who had undoubtedly contributed to the current gene pool of AfA, were considered as ancestral parental populations of AfA in this study. However, it was practically difficult to select proper populations as genetic donors to the gene pool of AfA since the extant populations in West Africa and Europe might not necessarily represent those $300 \mathrm{yr}$ ago, given the possible influence of genetic drift, selection, and demographic history. In this study, we chose the samples of Yoruba in Ibadan, Nigeria (YRI), and Utah residents with ancestry from northern and western Europe (CEU), to respectively represent those who contributed to the formation of AfA, largely due to the availability of phased genetic data for these two populations. Besides, an exploratory analysis including Human Genome Diversity Project (HGDP) populations (Li et al. 2008) also suggested that YRI and CEU are better choices for ancestral parental populations of AfA than the other populations with available genome-wide data (see Supplemental Text and Supplemental Fig. S3).

FRAPPE (Tang et al. 2005) was applied to the genomewide high-density SNP data (by taking $\mathrm{K}=2$ ), and the estimated European contribution to AfA was $21.65 \%$ at population level (Supplemental Figs. S4, S5). structure (Pritchard et al. 2000; Falush et al. 2003) analyses yielded virtually identical results. Based on the thinned data with 341,672 SNPs, the European contribution to the 1890 AfA was estimated to be $21.61 \%$ using PCA results (Supplemental Fig. S3D). These estimations were essentially consistent with those in previous studies (Smith et al. 2004; Xu et al. 2007; Bryc et al. 2010), although data sets analyzed were different.

\section{Identification of genomic regions with biased ancestry in AfA}

To estimate the distribution of genetic contributions of European and African ancestry to AfA across the genome, we used haplotypes of $88 \mathrm{CEU}$ and 88 YRI (the phased parents of trios, presumably unrelated, from HapMap3 data) to represent their ancestral parental populations. The identical monomorphic SNPs in CEU and YRI samples were removed for they could not provide valuable information in the local ancestry inference. HAPMIX (Price et al. 2009) was employed to estimate the locus-specific genetic contributions of the ancestral parental populations to AfA (see Methods) by taking $21.65 \%$ as the European contribution, as estimated by FRAPPE. Based on the likelihood given by HAPMIX, generation since admixture $(\lambda)$ was estimated to be $\lambda=7$ (an essentially hybrid isolation model), which was similar to those based on other AfA data sets (Smith et al. 2004; Price et al. 2009). Detailed analysis showed that $\lambda$ values for most individuals ranged from 1 to 12 , and could be explained by a continuous-gene-flow (CGF) model (see Supplemental Text and Supplemental Fig. S6). The locus-specific European ancestry proportion across the genome of AfA was estimated to be $21.68 \% \pm 0.75 \%$ (mean $\pm \mathrm{SD}$ ). The SD of locus-specific ancestral genetic contributions in this study is lower than those in any previous studies (Workman et al. 1963; Reed 1969; Blumberg and Hesser 1971; Tang et al. 2007; Basu et al. 2008; Bryc et al. 2010), which was not beyond our expectation since we used a much larger sample size.

The genomic regions showing excessive or reduced ancestry in the admixed population are likely to be signatures of natural selection (Tang et al. 2007; Basu et al. 2008; Bryc et al. 2010; Oleksyk et al. 2010). The loci showing strong deviation of European ancestry (3 SDs above or below the genome-wide average) were therefore identified as candidates of natural selection in this study. Four regions (2p22, 3q13, 6q26, 16q21) with excessive European influence and two regions (1p36, 2q37) with excessive African influence were observed in AfA genomes (Fig. 1). Each of the six regions was significantly different from the genome-wide average of ancestral contributions $\left(P<2.2 \times 10^{-16}, t\right.$-test $)$. The detailed annotations of the six candidate regions are presented in Table 1. Most genomic regions showing ancestry deviation can be replicated by an analysis with LAMP-ANC (see Supplemental Text; Supplemental Fig. S7), although it has lower accuracy than HAPMIX based on our simulated data.

A close examination of SNPs in the six regions showing biased ancestry revealed neither significant deviation from the Hardy-Weinberg expectation nor an unusual fraction of missing data, suggesting that the genotyping quality is unlikely the cause of this bias. In addition, the six regions did not overlap with previously reported long-ranged linkage disequilibrium (LD) blocks including inversions which may confound genome-wide scans for selection signals in admixed populations (Price et al. 2008), even though three short inversions have been found in one European

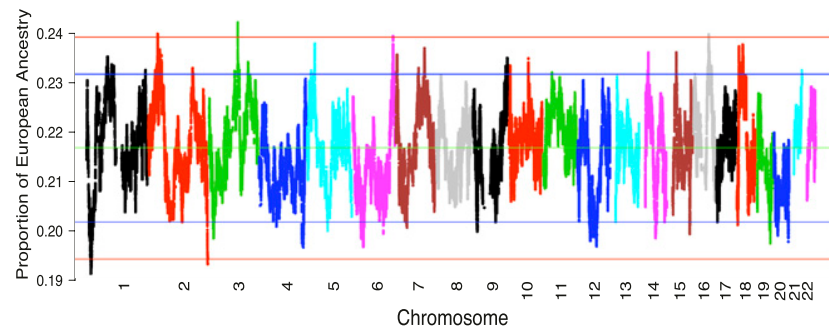

Figure 1. Genome-wide distribution of European ancestral contributions. Mean European ancestral contribution across 1890 African-American individuals at each SNP. (Green line) Estimated genome-wide mean European ancestral contribution (21.68\%). Blue bands indicate +2 and -2 SDs from the mean ancestral contribution and red bands indicate +3 and -3 SDs from the mean ancestral contribution.

\section{Genome Research} www.genome.org 
Table 1. Regions showing excess of European or African ancestry

\begin{tabular}{|c|c|c|c|c|c|c|c|c|}
\hline Regions & Position & $\begin{array}{l}\text { Excess } \\
\text { ancestry }\end{array}$ & $\begin{array}{l}\text { Size } \\
\text { (bp) }\end{array}$ & SNPs & $\begin{array}{c}\text { Highest } \\
\text { deviation }\end{array}$ & Genes & Pathways & $\begin{array}{l}\text { Related } \\
\text { diseases }\end{array}$ \\
\hline $1 p 36$ & $\begin{array}{l}\text { chr1:17409539.. } \\
21604321\end{array}$ & African & $4,194,783$ & 489 & 0.0253 & $\begin{array}{l}A K R 7 A 2^{\mathrm{a}}, \text { IGSF21, } \\
D D O S T^{\mathrm{a}}, \mathrm{HTR} 6 \\
\text { and others }\end{array}$ & $\begin{array}{l}\text { Diabetes pathways, } \\
\text { signaling by GPCR, } \\
\text { metabolism of amino } \\
\text { acids }\end{array}$ & $\begin{array}{l}\text { Diabetes, } \\
\text { pancreatic cancer }\end{array}$ \\
\hline $2 q 37$ & $\begin{array}{c}\text { chr2:241750403.. } \\
242568618\end{array}$ & African & 818,216 & 16 & 0.0231 & $\begin{array}{l}S E P T 2^{\mathrm{a}}, H D L B P^{\mathrm{a}} \\
P D C D^{\mathrm{a}} 1, F A R P 2 \\
\text { and others }\end{array}$ & $\begin{array}{l}\text { Signaling in immune } \\
\text { system, axon guidance, } \\
\text { metabolism of } \\
\text { nucleotides }\end{array}$ & $\begin{array}{l}\text { Bladder cancer, lung } \\
\text { cancer, coronary } \\
\text { atherosclerosis }\end{array}$ \\
\hline $2 \mathrm{p} 22$ & $\begin{array}{c}\text { chr2:37451925.. } \\
37508581\end{array}$ & European & 56,657 & 9 & 0.0230 & $\begin{array}{l}Q P C T,\left(E I F 2 A K 2^{\mathrm{a}}\right. \\
222 \mathrm{~kb})\end{array}$ & Influenza infection & Influenza infection \\
\hline $3 q 13$ & $\begin{array}{c}\text { chr3:116930811.. } \\
118313302\end{array}$ & European & $1,382,492$ & 216 & 0.0253 & LSAMP & Homophilic adhesion & Osteosarcoma \\
\hline $6 q 26$ & $\begin{array}{c}\text { chr6:163653158.. } \\
163653428\end{array}$ & European & 271 & 2 & 0.0225 & PACRG ${ }^{\mathrm{a}}$ & $\begin{array}{l}\text { Mediate proteasomal } \\
\text { degradation }\end{array}$ & $\begin{array}{l}\text { Juvenile Parkinson's } \\
\text { disease }\end{array}$ \\
\hline $16 q 21$ & $\begin{array}{c}\text { chr16:61214438.. } \\
61242497\end{array}$ & European & 28,060 & 9 & 0.0229 & NA & NA & NA \\
\hline
\end{tabular}

NA, not available.

${ }^{a}$ Genes associated with diseases. Genes in parentheses are strong candidates out of the chromosome location but closest.

individual in 1p36. Although the estimated locus-specific ancestral contributions across the genome are generally consistent with the study by Bryc et al. (2010), the three regions showing biased ancestry identified by them were only in moderate excess of African or European ancestry in this study, possibly due to the different samples and/or sample sizes between the two studies. Our estimations were also generally consistent with the genome-wide distribution of ancestry calculated in previous admixture mappings (Reich et al. 2005; Kao et al. 2008).

The region showing the strongest bias is located on $1 \mathrm{p} 36$, where African ancestry is over-represented. In this region, IGSF21 and $A K R 7 A 2$ are located next to the SNPs that show the strongest signals, respectively. IGSF21 belongs to the immunoglobin superfamily, while $A K R 7 A 2$ is involved in the detoxification of aldehydes and ketones, and is implicated in various cancers such as pancreatic cancer (Praml et al. 2008; Cui et al. 2009). Another region with over-represented African ancestry is 2q37, in which $P D C D 1$ is involved in signaling of the immune system and various diseases. The region showing the highest excessive European ancestry is located on 3q13, which only harbors LSAMP, a candidate of the tumor suppressor gene in human osteosarcomas, and is associated with coronary artery disease (Kresse et al. 2009; Yen et al. 2009). Interestingly, EIF2AK2, involved in influenza infection pathways (McAllister et al. 2010; Pereira et al. 2010), is located $\sim 200 \mathrm{~Kb}$ away from the peak (2p22) showing the second highest excessive European ancestry, which suggested the possible difference between African and European resistance to influenza. PACRG, located in 6q26, is associated with Parkinson's disease. However, the region in 16q21 showing excessive European ancestry did not contain any genes or known function elements.

\section{African / European components of ancestry in AfA}

The segments of African ancestry and those of the European ancestry in AfA, inferred by HAPMIX, were collectively referred to as African components of ancestry and European components of ancestry, respectively, each of which could be considered as an AAF or an ancestral European population (AEU) residing in America before admixture. The inference of AAF and AEU are credible given the accuracy of HAPMIX that is $>98 \%$ based on simulated data (see Supplemental Text).
Then population differentiation between AEU and each putative European parental population was calculated, with CEU showing the lowest $F_{\mathrm{ST}}$ with AEU $\left(F_{\mathrm{ST} \text { [AEU-CEU] }}=0.0005\right)$ among all putative parental populations. When 2648 Caucasian from GWAS data (referred to as CAU-GWAS) were considered, $F_{\mathrm{ST} \text { [AEU-CAU-GWAS] }}$ was 0.0006 , which was the second lowest among all values. Among all IAF, YRI showed the lowest $F_{\mathrm{ST}}$ with AAF $\left(F_{\mathrm{ST} \text { [AAF-YRI] }}=0.0007\right)$. When the observed $F_{\mathrm{ST}}$ 's were compared with those simulated under neutrality (see Methods), a different pattern emerged between European ancestry and African ancestry. For European ancestry, the observed $F_{\mathrm{ST}}$ between AEU and CEU (0.0005) was lower than that simulated (simulated $F_{\mathrm{ST} \text { [AEU-CEU] }}=0.0006$ ), and the genome-wide distribution of observed locus-specific $F_{\mathrm{ST}}$ did not deviate much from those simulated ( $P=0.042$, Kolmogorov-Smirnov test).

However, for African ancestry, the observed $F_{\mathrm{ST}}$ between AAF and YRI (0.0007) was higher than that simulated (simulated $F_{\mathrm{ST}}$ [AAF-YRI $=0.0006)$, and genome-wide distribution of locus-specific $F_{\text {ST [AAF-YRI] }}$ was significantly different from those simulated $(P<$ $2.2 \times 10^{-16}$, Kolmogorov-Smirnov test). In particular, a Q-Q plot between the observed and simulated locus-specific $F_{\mathrm{ST}}$ [AAF-YRI] showed an enrichment of SNPs with high $F_{\mathrm{ST}}$ at the tail of the observed locus-specific $F_{\text {ST }}$ (Supplemental Fig. S8), suggesting a possible role of natural selection. The results remain essentially unchanged when bottlenecks for African ancestry were assumed in our simulations.

\section{Identification of regions highly differentiated between $\mathrm{AAF}$ and African}

Since the African immigrants left for America, they might have experienced a completely different population history compared with indigenous Africans. The high mortality of AfA during the slavery era (Meltzer 1993; Stannard 1993; Thomas 1999) suggested a possible presence of strong selective pressures. According to the theory of neutrality, $F_{\mathrm{ST}}$ is largely influenced by demographic history which affects all loci similarly (Weir and Cockerham 1984; Kimura 2003), if not equally. In contrast, the force of positive selection acts in a locus-specific manner and tends to increase $F_{\mathrm{ST}}$ (Nielsen 2005), which has been widely used to detect the positive selection in various studies (Akey et al. 2002; Oleksyk et al. 2010). In this study, we calculated the locus-specific $F_{\mathrm{ST}}$ between AAF and 
YRI (Supplemental Fig. S9). However, loci with a very low minor allele frequency (MAF) may be subjected to sampling error and statistical error; therefore, the SNPs with MAF $<0.05$ in AAF or YRI were removed from further analyses.

The genome-wide distribution of $F_{\mathrm{ST}}$ between AAF and YRI for 401,599 autosomal SNPs is presented in Figure 2A. In spite of the low differentiation between AAF and YRI, a substantial proportion of SNPs was located at the right tail of the distribution. The functional annotations of the most differentiated SNP clusters (99.99th percentile; $F_{\mathrm{ST}}>0.0452$ ) are listed in Table 2 . Although it is reported that $F_{\mathrm{ST}}$ of an individual marker was too variable (Weir et al. 2005), the four most significant regions $(7 \mathrm{q} 21,6 \mathrm{p} 21-22,1 \mathrm{q} 22$, and 11p15) carrying multiple highly differentiated SNPs should be indicative. The 7q21 region harbors two genes: CD36 and SEMA3C. CD36 directly mediates cytoadherence of Plasmodium falciparum parasitized erythrocytes and it binds long chain fatty acids and may function in the transport and/or as a regulator of fatty acid transport (Oquendo et al. 1989; Baruch et al. 1996; Erdman et al. 2009). It was reported that $C D 36$ has been subjected to positive selection for malaria or some unknown selection pressures (Aitman et al. 2000; Omi et al. 2002, 2003; Fry et al. 2009). SEMA3C, induced by ADAMTS1, promotes the migration of cancer cells (Esselens et al. 2010). The 6p21-22 region, harboring human major histocompatibility complex (MHC), also showed an overrepresentation of African ancestry in this study (although $<3 \mathrm{SD}$ ) and has been reported under selection in various studies (Garrigan and Hedrick 2003; Tang et al. 2007). MUC1, located in 1q22, is involved in signaling by PDGF and serves a protective function by binding to pathogens (Davila et al. 2010; Li et al. 2010). HBB and $H B D$, located in $11 \mathrm{p} 15$, have been subjected to balancing selections because their mutations protected against malaria according to numerous studies (Ashley-Koch et al. 2000; Wood et al. 2005).

Ingenuity pathway analysis (IPA) was particularly helpful in exploring the function and pathways of the selection-candidate

A

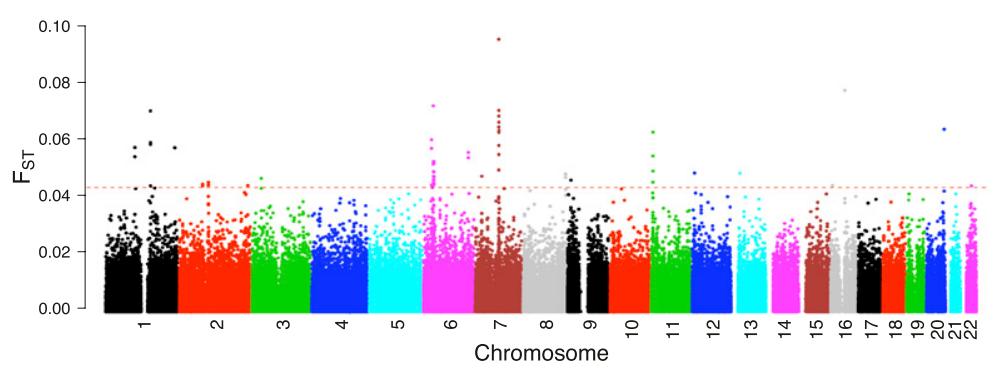

B

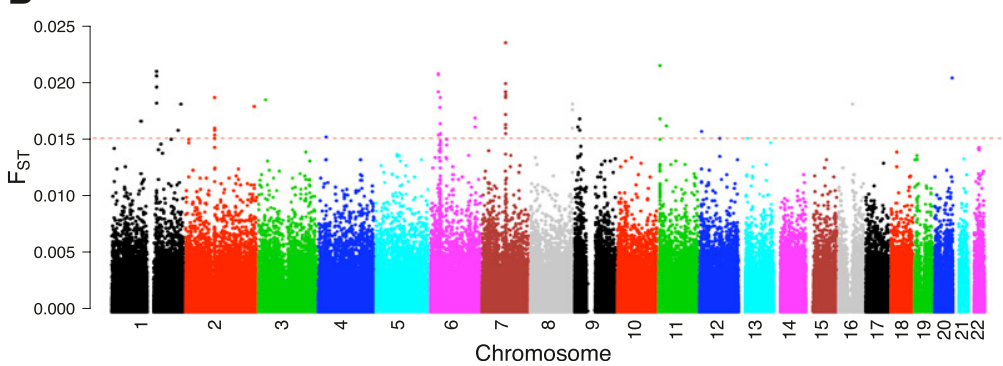

Figure 2. (A) Genomic distribution of $F_{\mathrm{ST}}$ between AAF and YRI. (B) Genomic distribution of $F_{\mathrm{ST}}$ between AfA and rAfA. Dashed red horizontal line indicates the cutoff threshold (99.99th percentile). Locus-specific $F_{\mathrm{ST}}$ between YRI and CEU were calculated when MAF $>0.05$ in both populations. The rAfA was constituted according to the ancestry proportion of CEU and YRI under neutrality. genes in the context of higher-order cellular and molecular mechanisms. The 402 SNPs with the highest $F_{\mathrm{ST}}$ (99.90th percentile; $\left.F_{\mathrm{ST}}>0.0287\right)$ were subjected to IPA analysis, whose results showed that genes involved in metabolic diseases were the most significantly enriched $\left(P=1.51 \times 10^{-16}\right)$ among all function classes, followed by the genes involved in endocrine system disorders $(P=$ $\left.2.23 \times 10^{-16}\right)$, immunological diseases $\left(P=9.30 \times 10^{-12}\right)$, and genetic disorders $\left(P=5.67 \times 10^{-11}\right)$. Antigen presentation pathway was the most significantly enriched $\left(P=1.95 \times 10^{-4}\right)$, followed by allograft rejection signaling $\left(P=4.69 \times 10^{-3}\right)$, Graft-versus-host disease signaling $\left(P=4.69 \times 10^{-3}\right)$, and autoimmune thyroid disease signaling $\left(P=5.35 \times 10^{-3}\right)$. All of the four aforementioned pathways are related to the immune system, which might reflect a great environmental differentiation between Sub-Saharan Africa and North America. We also conducted IPA on 4011 SNPs showing the highest $F_{\mathrm{ST}}$ (99.00th percentile; $\left.F_{\mathrm{ST}}>0.0162\right)$, which yielded results similar to those with $F_{\mathrm{ST}}>0.0287$ (99.90th percentile). And two additional pathways emerged: IL-9 signaling pathway $(P=8.01 \times$ $\left.10^{-3}\right)$ and EGF signaling pathway $\left(P=6.38 \times 10^{-3}\right)$.

\section{Reconstituted African American (rAfA) and its difference with AfA}

We then compared the AfA genome with that of reconstituted African Americans (rAfA) using genotypes of YRI and CEU. The rationale is that the former have been subjected to possible natural selection, while the latter have not. In particular, the allele frequencies of rAfA were estimated at each locus using YRI and CEU for the given level of admixture (21.68\%), assuming no natural selection after admixture. The candidates identified under selection in this way could avoid potential errors introduced in the inference of ancestry. The genome-wide distribution of $F_{\mathrm{ST}}$ between AfA and rAfA is shown in Figure 2B. Overall, 81\% of the SNPs showing the highest difference between AAF and IAF could be validated in the comparison between AfA and rAfA. In particular, these main $F_{\mathrm{ST}}$ peaks between AAF and YRI are essentially the same as those between AfA and rAfA, which indicated that almost all the selection signals identified by comparing AfA and rAfA originated from AAF or IAF. We also used CAU-GWAS instead of CEU to construct rAfA, with the genomic distribution of $F_{\mathrm{ST}}$ similar to that using CEU (Supplemental Fig. S10).

Next, we reconstructed a rAfA population using a set of putative parental populations. First, we constructed an African parental population of AfA (APP) using 64\% Yoruba, 19\% Mandenka, and 14\% Bantu according to previously reported ancestral contributions to AAF (Zakharia et al. 2009). Then we used genotypes of the APP and CAU-GWAS to reconstruct rAfA. We obtained the genome-wide distribution of $F_{\mathrm{ST}}$ between AfA and rAfA (Supplemental Fig. S11). Although the population differentiation between this rAfA and AfA is higher than that based on the two aforementioned rAfAs, the genome-wide distribution of $F_{\mathrm{ST}}$ is similar to that using only two pure parental populations.

\section{Genome Research}

www.genome.org 
Table 2. Regions with highly differentiated allele frequency between AAF and YRI $\left(F_{\mathrm{ST}}>0.0452\right)$

\begin{tabular}{|c|c|c|c|c|c|c|c|}
\hline $\begin{array}{l}\text { Regions } \\
\text { or SNPs }\end{array}$ & Position & $\begin{array}{l}\text { Size } \\
\text { (bp) }\end{array}$ & SNPs & $\begin{array}{l}\text { Highest } \\
F_{\mathrm{ST}}\end{array}$ & Genes & Pathways & $\begin{array}{l}\text { Related } \\
\text { disease }\end{array}$ \\
\hline $1 \mathrm{p} 21$ & $\begin{array}{c}\text { chr1:100125058.. } \\
100183875\end{array}$ & 58,817 & 2 & 0.0562 & $A G L^{\mathrm{a}}$ & $\begin{array}{l}\text { Metabolism of } \\
\text { carbohydrate }\end{array}$ & $\begin{array}{l}\text { Glycogen storage } \\
\text { disease }\end{array}$ \\
\hline $1 q 22$ & $\begin{array}{l}\text { chr1:153401959.. } \\
153464086\end{array}$ & 62,127 & 4 & 0.0692 & $\begin{array}{l}T_{H B S 3^{\mathrm{a}}, M U C 1^{\mathrm{a}}}, \\
\text { MTX1, TRIM46, } \\
\text { KRTCAP2 }\end{array}$ & Signaling by PDGF & $\begin{array}{l}\text { Stomach cancer, breast } \\
\text { cancer, osteosarcoma }\end{array}$ \\
\hline $\begin{array}{l}\text { rs120 } \\
\quad 94201\end{array}$ & chr1:236509336 & 1 & 1 & 0.0561 & $\left(Z P 4^{\mathrm{a}} 389 \mathrm{~kb}\right)$ & NA & $\begin{array}{l}\text { Hypertension, nonalcoholic } \\
\text { fatty liver }\end{array}$ \\
\hline rs7642575 & chr3: 31400165 & 1 & 1 & 0.0453 & $\begin{array}{l}\left(S T T 3 B, O S B P L 10^{\mathrm{a}}\right. \\
149 \mathrm{~kb})\end{array}$ & NA & Peripheral arterial disease \\
\hline $6 p 21-p 22$ & $\begin{array}{l}\text { chr6:26554684.. } \\
\quad 33961049\end{array}$ & $7,406,365$ & 11 & 0.0711 & $\begin{array}{l}H L A-B^{\mathrm{a}}, H L A-C, \\
E H M T 2^{\mathrm{a}}, H L A-D P A 1^{\mathrm{a}}, \\
H L A-D R B 5, E H M, \\
B T N 3 A 3 \text { and others }\end{array}$ & $\begin{array}{l}\text { Signaling by GPCG, } \\
\text { signaling in immune } \\
\text { system, HIV infection, } \\
\text { diabetes pathway }\end{array}$ & $\begin{array}{l}\text { HIV, Crohn's disease, } \\
\text { rheumatoid arthritis, } \\
\text { juvenile idiopathic arthritis, } \\
\text { colorectal cancer, systemic } \\
\text { sclerosis }\end{array}$ \\
\hline $6 q 25$ & $\begin{array}{c}\text { chr6:151555551.. } \\
151569258\end{array}$ & 13,707 & 2 & 0.0545 & $\left(A K A P 12^{\mathrm{a}} 40 \mathrm{~kb}\right)$ & Cell growth & $\begin{array}{l}\text { Hypertension, hemorrhagic } \\
\text { stroke }\end{array}$ \\
\hline $\begin{array}{l}\text { rs104 } \\
99542\end{array}$ & chr7: 22235870 & & 1 & 0.04606 & $R A P G E F 5^{\mathrm{a}}$ & GTP/GDP-regulation & Thyroid stimulating hormone \\
\hline $7 q 21$ & $\begin{array}{c}\text { chr7:79768487.. } \\
80482597\end{array}$ & 714,110 & 10 & 0.0946 & $C D 36^{\mathrm{a}}$, SEMA3C & $\begin{array}{l}\text { Metabolism of } \\
\text { lipids and lipoprotein }\end{array}$ & Metabolic syndrome, malaria \\
\hline $8 q 24$ & $\begin{array}{c}\text { chr8:143754039.. } \\
143758933\end{array}$ & 4,894 & 2 & 0.04679 & $P S C A^{\mathrm{a}}$ & NA & $\begin{array}{l}\text { Prostate cancer, bladder } \\
\text { cancer, gastric cancer }\end{array}$ \\
\hline $11 \mathrm{p} 15$ & $\begin{array}{l}\text { chr11:5034229.. } \\
\quad 5421456\end{array}$ & 387,227 & 3 & 0.0617 & $\begin{array}{l}H B B^{\mathrm{a}}, H B D^{\mathrm{a}}, H B E 1^{\mathrm{a}}, \\
H B G 2, O R 51 / 1 \\
\text { and others }\end{array}$ & Signaling by GPCR & $\begin{array}{l}\text { Sickle cell disease, beta- } \\
\text { thalassemia, malaria }\end{array}$ \\
\hline rs4883422 & chr12:7189594 & 1 & 1 & 0.04721 & CLSTN3 & NA & NA \\
\hline rs6491096 & chr13:25488362 & 1 & 1 & 0.04716 & ATP8A2 & NA & NA \\
\hline rs1075875 & chr16: 47595721 & 1 & 1 & 0.0766 & (CBLN1 277kb) & NA & NA \\
\hline rs6015945 & chr20:59319574 & 1 & 1 & 0.0627 & $\mathrm{CDH} 4^{\mathrm{a}}$ & Cell junction organization & Alzheimer's disease \\
\hline
\end{tabular}

NA, not available.

${ }^{a}$ Genes associated with diseases. Genes in parentheses are strong candidates out of the chromosome location but closest.

\section{Further evidence for positive selection in AAF and African}

Since the force of positive selection acts in a locus-specific manner and tends to increase $F_{\mathrm{ST}}$ (Nielsen 2005), we hypothesized that positive selection preferentially acted upon functionally important loci over the others in the genome, thus leading to an enrichment of functional SNPs in the high $F_{\mathrm{ST}}$ bin (Barreiro et al. 2008). Here, we investigated the enrichment of different SNP classes among the high $F_{\mathrm{ST}}$ bin (top first percentile among all SNPs, $F_{\mathrm{ST}}>0.0164$ ) between AAF and YRI.

The SNPs, based on their location and function relative to the genes, were classified into nongenic, genic, intronic, 3'UTR, 5'UTR, synonymous, nonsynonymous, coding, transcriptonic, neargene-3, and near-gene-5 according to UCSC annotation. We found that $F_{\mathrm{ST}}$ distributions of each SNP category were not significantly different from those of nongenic SNPs. However, the proportion of genic SNPs among the high $F_{\mathrm{ST}}$ bin (top first percentile among all SNPs, $\left.F_{\mathrm{ST}}>0.0164\right)$ is significantly higher than that of nongenic SNPs $\left(\chi^{2}\right.$ test, $P=0.046$ ) (Fig. 3). Notably, this excess is particularly marked for transcriptonic SNPs ( $\chi^{2}$ test, $\left.P=0.004\right)$ (Fig. 3). The proportion of synonymous SNPs in the high $F_{\mathrm{ST}}$ bin was 1.22 -fold higher than the expectation under neutrality, which could attribute to the LD of those SNPs with loci under selection (a phenomenon known as hitchhiking). Similar observations could be made when the thresholds for the high $F_{\mathrm{ST}}$ bin were set at the top 5\% $\left(F_{\mathrm{ST}}>0.0083\right)$ or the top $0.1 \%$ $\left(F_{\mathrm{ST}}>0.0304\right)$ (Supplemental Figs. S12, S13), and the conclusions still held when the SNPs with MAF $>0.05$ in both YRI and AAF were examined (Supplemental Fig. S14). The significant enrichment of high $F_{\mathrm{ST}}$ loci in the SNP categories with genetic functions supports the presence of positive selection either in AAF or in YRI, or both.

\section{Discussion}

Admixed populations such as AfA provide a unique opportunity to study very recent natural selection, as their genomes are donated by long-diverged continental ancestries and may have been subjected to novel environmental challenges. The first strategy, detecting an excessive or decreased ancestry contribution from its ancestral parental populations, has been used in several recent studies (Tang et al. 2007; Basu et al. 2008; Bryc et al. 2010). However, natural selections before admixture cannot be detected by this approach because the distribution of ancestry across the

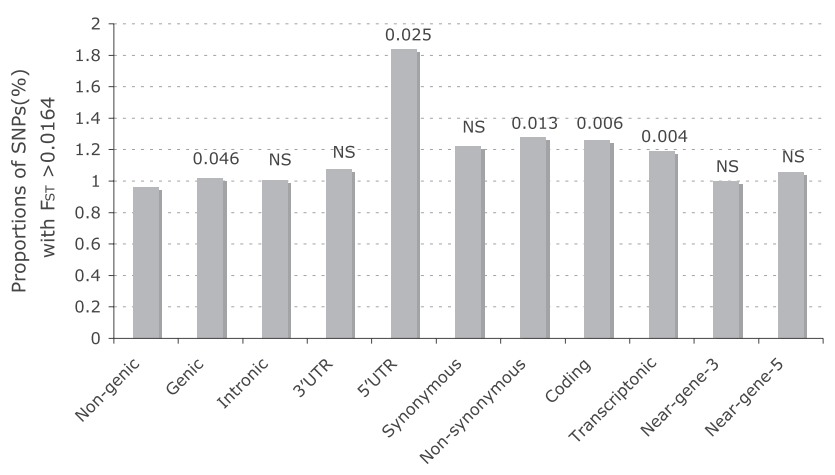

Figure 3. Enrichment of high $F_{S T}$ loci for different SNP categories. Observed excess of high $F_{S T}$ loci in different SNP classes, with respect to nongenic class, in the high $F_{\mathrm{ST}}$ bin (99th percentile; $F_{\mathrm{ST}}>0.0164$ ). The values on the bar are $P$-values of $\chi^{2}$ tests. NS, not significant. 
admixed genomes would not be affected by such selections. Therefore, we developed a new strategy, which examined selections since the African ancestry left for America (including selections both pre- and post-admixture). The candidate genes under selection identified by our new strategy were also confirmed in an analysis of allele frequency differentiation between rAfA and AfA (although the two analyses are not completely independent).

Above all, we have identified six regions showing an excess of African or European ancestry using the first strategy. The highest ancestry deviation among all regions showing an excess of African and European ancestry is $<0.026$, which is lower than the values of any previous studies on the admixed populations in the New World (Workman et al. 1963; Reed 1969; Blumberg and Hesser 1971; Tang et al. 2007; Basu et al. 2008; Bryc et al. 2010). For example, the African ancestry deviation even exceeds 0.14 in Puerto Ricans according to a study by Tang et al. (2007), which is more than fivefold higher than that in this study. We attribute the low ancestry deviation to the much larger sample size, denser markers, more accurate phased data using trios, and more powerful statistical methods used in this study. Based on the maximum deviation regions, we estimated that the highest selection coefficient is approximately 0.002 (assuming 12 generations since admixture under a CGF model). In fact, the real selection coefficient could be much lower than 0.002 considering the statistics and evolutionary noises. These results are reasonable considering the fact that there has been a much lower mortality rate of AfA in the last $200 \mathrm{yr}$ compared with that during the Atlantic slave trade.

Secondly, we identified a large number of genes with highly differentiated allele frequencies between AAF and YRI using our new approach. These genes do not overlap with those identified by the former approach, suggesting the different environmental pressures AfA experienced before and after population admixture. IPA analysis of SNPs with high population differentiation between AAF and YRI showed that genes involved in metabolic diseases $(P=$ $\left.1.51 \times 10^{-16}\right)$, endocrine system disorder $\left(P=2.23 \times 10^{-16}\right)$, immunological diseases $\left(P=9.30 \times 10^{-12}\right)$, and genetic disorder $(P=$ $5.67 \times 10^{-11}$ ) were significantly enriched. Especially, we found that genes such as PSCA, ZP4, and AKAP12 were associated with AfAspecific high-risk diseases such as hypertension and prostate cancer (Smith and O'Brien 2005; Goran 2008). Five genes (CD36, HBB, HBD, $H L A-B, H L A-D R)$, whose mutations protect against malaria, are also located in the highly differentiated regions between AAF and IAF.

Compared with Caucasians, AfA have a higher mortality rate for all cancers combined and for most major cancers (Jemal et al. 2006), as well as a higher risk of obesity-related diseases such as diabetes, hypertension, and prostate cancer (Goran 2008). Interestingly, many genes located in selection-candidate regions identified by the novel approach are associated with AfA ethnic high-risk diseases such as hypertension, prostate cancer, and systemic sclerosis. Especially, one of the most significantly differentiated SNPs (rs2294008; $F_{\mathrm{ST}}=0.04561$ ) between AAF and YRI, located in $8 \mathrm{q} 24$, is a missense mutation c.57T>C (p.Met1Thr) in PSCA and was reported to be associated with gastric and bladder cancer (Sakamoto et al. 2008; Matsuo et al. 2009; Wu et al. 2009). Many studies also reported that multiple loci in $8 \mathrm{q} 24$ were associated with prostate cancer in AfA (Freedman et al. 2006; Al Olama et al. 2009; Yeager et al. 2009). We proposed a hypothesis that most of the genes associated with AfA ethnic diseases may have played an important role in AfA's adaptation to the local environment and thus show higher population differentiation between AAF and IAF. Further analysis of the $8 \mathrm{q} 24$ region would provide new insights into the etiology and evolutionary history of these cancers.
Among the selection-candidate genes detected by genomewide locus specific $F_{\mathrm{ST}}$ between AAF and YRI, five genes (CD36, $H B B, H B D, H L A-B, H L A-D R)$ have been reported to be subjected to natural selection probably due to malaria (Kwiatkowski 1999, 2005). Because of the strong selection pressure of malaria, loss-offunction or abnormality of these genes was supposed to increase the survival rate of an individual living in Africa. Some mutations in these genes have reached much higher frequencies in Africans compared with those in areas of low incidence of malaria. However, these mutations that defend against malaria could become a disadvantage in AfA because malaria is no longer a strong selection pressure in North America, and these mutations could even lead to morbidity or mortality (Platt et al. 1994). We hypothesize that frequencies of these mutations would have decreased in AAF compared with those in IAF due to their disadvantage in AfA.

Next, we examined this hypothesis in the empirical data. Since the functional mutations in these genes were not genotyped in this study, we examined the SNPs strongly linked (linkage disequilibrium) with these mutations instead of these mutations themselves. It is well known that rs3211938 is a nonsense mutation c. $1389 \mathrm{~T}>\mathrm{G}$ (p.Tyr325X) in CD36 and has been subjected to natural selection because of malaria or some other environmental factors in African (Aitman et al. 2000; Omi et al. 2003; Erdman et al. 2009; Fry et al. 2009). We found three SNPs that are highly differentiated between AAF and YRI (Supplemental Table S1) in 7q21 and are strongly linked with rs3211938 (each with $\mathrm{r}^{2}>0.4$ in YRI). Interestingly, we did observe that the frequencies of the alleles linked with rs3211938(G), the derived allele, were much lower in AAF compared with those in YRI (Supplemental Table S1). Another example, rs334 is a missense mutation c.70A>T (p.Glu7Val) in $H B B$, which leads to sickle cell anemia (MIM 603903) (AshleyKoch et al. 2000; Winichagoon et al. 2000; Wood et al. 2005), one of the most well-studied genetic disorders. rs7952293, one of the SNPs showing high $F_{\mathrm{ST}}$ between AAF and YRI, was strongly linked with rs334 $\left(\mathrm{r}^{2}=0.237\right.$ in YRI). In particular, the haplotype constructed by rs7952293(A) and rs334(T) accounted for $86.67 \%$ of the haplotypes containing rs334(T) in YRI. We observed that the frequency of rs7952293(A) in AAF (0.2261) was lower compared with that in YRI (0.3172), which also supports the hypothesis that frequencies of alleles protecting against malaria in AAF are lower than those in IAF. The other three genes were not examined using the same procedure because the frequencies of mutations on these genes are too low to find strong-linked representative SNPs.

Our study takes advantage of both large sample size and highdensity genome-wide data. However, our analysis demonstrated that the maximum deviation showing an excess of African or European ancestry was small $(<2.6 \%)$. Detecting such weak selection signals in an admixed population such as AfA is a big challenge, which needs a large sample size as in this study, or even a larger sample size, to distinguish the real signals from the ancestry deviation caused by genetic drift and sampling error. Therefore, we propose that any study in the future trying to detect such weak selection signals in AfA or other recently admixed populations should collect at least thousands of samples. With the new strategy, we detected a lot of genes associated with AfA-specific highrisk diseases such as hypertension and prostate cancer, and we also detected five genes whose mutations are against malaria. This new approach is powerful in detecting natural selection both before and after the establishment of AfA and can be applied to other admixed populations such as Latinos in the New World and the Uyghurs in Asia (Xu and Jin 2008; Xu et al. 2008; Xu et al. 2009).

\section{Genome Research}




\section{Methods}

\section{Data assembly and quality control}

The genotypic data were obtained from the International HapMap Project (HapMap; http://www.hapmap.org), the Human Genome Diversity Project (HGDP;http://www.cephb.fr/en/hgdp), and Illumina iControlDB (http://www.illumina.com), respectively. The combined data set processed with PEAS v1.0 (Xu et al. 2010) includes the genotypic data of 588 HapMap samples (87 ASW, 167 YRI, $165 \mathrm{CEU}, 85 \mathrm{CHD}, 84 \mathrm{CHB}$ ) (The International HapMap Consortium 2007; Altshuler et al. 2010), 300 HGDP samples (156 indigenous European, 102 indigenous African, and 42 Amerindian) (Li et al. 2008), 2161 AfA, and 3294 Caucasians (referred to as CAUGWAS) from iControlDB genotyped by the Illumina 550K Beadarray. The samples from iControlDB have passed Illumina's rigorous quality control and have been used as controls in five genomewide association studies.

ASW from HapMap and AfA from iControlDB were merged into one AfA population, and Yoruba from HGDP was collected from Nigeria and therefore was merged with YRI from HapMap in subsequent analyses. The following samples were removed from the data set: (1) the relatives based on sample information or PLINK (Purcell et al. 2007) result (IBD > 0.2), (2) individuals identified as outliers of each population (except AfA) based on the top 10 principal components of PCA analysis (SD > 6), (3) AfA individuals with $>2 \%$ Native-American/East-Asian, (4) AfA individuals with $>99 \%$ European contribution, which are likely to be descendents of individuals of European ancestry, (5) AfA individuals with $>99 \%$ African contribution, in which recent African immigrants could not be practically identified (Bryc et al. 2010).

These filtered samples described above were merged and the SNPs sharing reference SNP ID (rs) and vendor-specified strands were kept in combined data. Then, the data set was further filtered for individuals with $>10 \%$ missing genotypes and SNPs with $>10 \%$ missing data, as well as Hardy-Weinberg disequilibrium $(P<2 \times$ $10^{-6}$ ) within each population except AfA. The final data set is composed of 503,694 SNPs (491,526 autosomal SNPs) shared by 5210 individuals from 21 population groups, with a total genotyping call rate of $99.74 \%$.

\section{Populations and samples}

Overall, 1890 unrelated AfA samples with no ancestry outside of Africa and Europe were studied, among which 1838 individuals were downloaded from iControlDB, and another 52 individuals were from the International HapMap Project (Altshuler et al. 2010). In addition, 113 YRI from HapMap (Altshuler et al. 2010) and 102 IAF in seven different groups collected from HGDP (Li et al. 2008) were merged, representing the extant Africans, while 113 CEU from HapMap (Altshuler et al. 2010) were merged with 156 Europeans in eight different groups collected from HGDP, representing the extant Europeans. In total, 2648 CAU-GWAS samples from iControlDB were taken as another representation of the extant Europeans. In addition, $84 \mathrm{CHB}$ and $85 \mathrm{CHD}$ represented populations from East Asia, and 24 pure Amerindians from HGDP represented Native American.

\section{Population genetic analysis}

In order to reduce the LD between markers, those with $\mathrm{r}^{2}>0.5$ were removed, calculated in a sliding window of 50 SNPs, and shifted every five SNPs (see Supplemental Text). This process reduced the original data set to 341,672 autosomal SNPs. Based on these thinned markers, principal component analysis (PCA) was performed at the individual level using smartpca, from the package EIGENSOFT (Patterson et al. 2006). Individual ancestry proportion was estimated using FRAPPE, which implements an expectation- maximization (EM) algorithm (Tang et al. 2005). FRAPPE was run on all 491,526 SNPs with 10,000 iterations by setting K from 2 to 4. We also ran structure (Falush et al. 2003) on SNPs with intermarker distance $>1 \mathrm{M}$ (see Supplemental Text). Genetic difference between populations was measured using $F_{\mathrm{ST}}$ following Weir and Cockerham (Weir and Cockerham 1984), which accounts for differences in the sample size in each population. The locus-specific $F_{\mathrm{ST}}$ between any two populations was also calculated using the same formula.

\section{Locus-specific ancestry inference}

Various methods and software have been developed for inferring locus-specific ancestry based on high-density SNP data, such as ANCESTRYMAP (Patterson et al. 2004), SABER (Tang et al. 2006), LAMP and LAMP-ANC (Sankararaman et al. 2008b), uSWITCH and uSWITCH-ANC (Sankararaman et al. 2008a), HAPAA (Sundquist et al. 2008), and HAPMIX (Price et al. 2009). A simple analysis showed that HAPMIX outperformed other methods with implemented software based on our simulated data (see Supplemental Text). Therefore, HAPMIX was used to infer locus-specific ancestry in AfA in this study. We also used LAMP-ANC to do a similar analysis since it also performs very well.

The phased data of HapMap 3 were downloaded from the HapMap website (Altshuler et al. 2010). We used haplotypes of 88 CEU and 88 YRI (all from trio samples) representing the European and African ancestral populations, respectively, in the subsequent analysis. The mean European ancestry proportion in AfA $(\theta)$, which is a required input parameter for HAPMIX, was based on the estimation of FRAPPE. Generation since admixture $(\lambda)$ with the largest likelihood was taken as its estimation. By running HAPMIX in diploid mode, we obtained the haplotypes and ancestry segments for each AfA individual. Then we reconstructed an AAF and an AEU using inferred chromosomal segments of African ancestry and those of European ancestry in AfA, respectively. In brief, we constructed AAF using only those chromosomal segments with pure African ancestry. For each given SNP, the allele frequency of AAF was calculated based on the available genotypes with African ancestry across all AfA. This procedure was also applied to the construction of AEU using chromosomal segments with pure European ancestry.

\section{Simulation of AfA and its parental populations}

Under selective neutrality, the genetic drift of the admixed population and its parental populations contribute to the variation of ancestry proportion and population differentiation among loci (Weir and Cockerham 1984; Long 1991). Therefore, we performed an extensive forward-time simulation to explore the potential impact of genetic drift on the locus-specific population differentiations between AAF and YRI, as well as that between AEU and CEU. In this simulation, recombination was introduced according to the genetic map adapted from HapMap (release \#22) (The International HapMap Consortium 2007), and mutation was ignored given the short history of AfA. The effective population sizes $\left(N_{\mathrm{e}}\right)$ of each population was obtained from the HapMap website (Altshuler et al. 2010). In particular, $N_{\mathrm{e}}$ for African, European, and AfA were set to 17,094, 11,418, and 17,094, respectively. A CGF model (Supplemental Fig. S15) was used based on previous studies (Pfaff et al. 2001; Price et al. 2009).

The aforementioned phased data of $88 \mathrm{YRI}$ and $88 \mathrm{CEU}$ were taken respectively as the genotypes of common African ancestry and common European ancestry before population admixture. We simulated individuals of AfA by constructing their genomes from a mosaic of haploid YRI and haploid CEU genomes. The generations since admixture $(\lambda)$ were set to 12 according to a CGF model based on previous reports (Pfaff et al. 2001; Price et al. 2009), which 
was also supported by our observations (Supplemental Fig. S6). The gene flow $(\alpha)$ that African ancestry received from European each generation was calculated by $\alpha=1-\left(m_{1}\right)^{1 / \mathrm{t}}$, in which $m_{1}$ represents the mean proportion of European ancestry in AfA. Both African and European parental populations evolved 12 generations simultaneously. Finally, genotypes of 113 European, 113 African, and $1890 \mathrm{AfA}$, as well as their SNP-specific ancestral status, were output to match the sample sizes of the data. Based on the primary simulation, we performed extended simulations by setting a bottleneck event in the first generation during which $N_{\mathrm{e}}$ for AfA were reduced to $8000,5000,3000,2000$, and 1000 , respectively.

\section{Function annotations and ingenuity pathway analysis (IPA)}

Genomic regions that deviated from genome-wide ancestral contributions or with extremely high $F_{\mathrm{ST}}$ were annotated based on the HapMap website (Thorisson et al. 2005). The SNPs showing substantial population differentiation were interrogated for network and functional interrelatedness using the IPA version 8.5 software tools. This software searches for information on genes in the Ingenuity Pathways Knowledge Base, a repository of molecular interactions, regulatory events, gene-to-phenotype associations, and chemical knowledge, all collected from the full text of the peerreviewed life science literature. With IPA, we can analyze data in the context of molecular mechanisms, identify key mechanistic differences between subpopulations, and further relate molecular events to higher-order cellular and disease processes.

\section{Statistical analysis}

All statistical computation and graphics were performed using $\mathrm{R}$ version 2.9 (Ihaka and Gentleman 1996). Kolmogorov-Smirnov tests were performed to compare the empirical distributions of locus-specific $F_{\mathrm{ST}}$ with those simulated, and $\chi^{2}$ tests were performed to test the over-representation of each SNP category compared with nongenic SNPs among the high $F_{\mathrm{ST}}$ bin.

\section{Acknowledgments}

S.X. was supported by the National Science Foundation of China (30971577, 31171218), Shanghai Rising-Star Program (11QA1407600), and Science Foundation of The Chinese Academy of Sciences (KSCX2-EW-Q-1-11, KSCX2-EW-R-01-05, KSCX2-EWJ-15-05). L.J. was supported by the National Science Foundation of China (30890034, 30625016) and the Science and Technology Commission of Shanghai Municipality (09540704300). S.X. is a Max-Planck Independent Junior Research Group Leader and a member of the CAS Youth Innovation Promotion Association. S.X. also gratefully acknowledges the support of the K.C. Wong Education Foundation, Hong Kong. B.W. is a senior author of the Harvard group. This work was also supported by the MoST International Cooperation Base of China.

Authors' contributions: S.X. and L.J. conceived and designed the study. H.W. collected genotype data from the Illumina iControl Database (iControlDB). W.J. performed data analysis, with contributions from S.X. Y.Y., Y.S., and B.W. performed IPA analysis. S.X. and W.J. interpreted the data. W.J., S.X., and L.J. wrote the paper. All authors read and approved the final manuscript.

\section{References}

Adams J, Ward RH. 1973. Admixture studies and the detection of selection. Science 180: 1137-1143.

Aitman TJ, Cooper LD, Norsworthy PJ, Wahid FN, Gray JK, Curtis BR, McKeigue PM, Kwiatkowski D, Greenwood BM, Snow RW, et al. 2000. Malaria susceptibility and CD36 mutation. Nature 405: 1015-1016.
Akey JM. 2009. Constructing genomic maps of positive selection in humans: Where do we go from here? Genome Res 19: 711-722.

Akey JM, Zhang G, Zhang K, Jin L, Shriver MD. 2002. Interrogating a highdensity SNP map for signatures of natural selection. Genome Res 12: 1805-1814.

Al Olama AA, Kote-Jarai Z, Giles GG, Guy M, Morrison J, Severi G, Leongamornlert DA, Tymrakiewicz M, Jhavar S, Saunders E, et al. 2009. Multiple loci on 8q24 associated with prostate cancer susceptibility. Nat Genet 41: 1058-1060.

Altshuler DM, Gibbs RA, Peltonen L, Altshuler DM, Gibbs RA, Peltonen L, Dermitzakis E, Schaffner SF, Yu F, Peltonen L, et al. 2010. Integrating common and rare genetic variation in diverse human populations. Nature 467: 52-58.

Ashley-Koch A, Yang Q, Olney RS. 2000. Sickle hemoglobin (HbS) allele and sickle cell disease: A HuGE review. Am J Epidemiol 151: 839-845.

Balaresque PL, Ballereau SJ, Jobling MA. 2007. Challenges in human genetic diversity: Demographic history and adaptation. Hum Mol Genet 16: R134-R139.

Barreiro LB, Laval G, Quach H, Patin E, Quintana-Murci L. 2008. Natural selection has driven population differentiation in modern humans. Nat Genet 40: $340-345$.

Baruch DI, Gormely JA, Ma C, Howard RJ, Pasloske BL. 1996. Plasmodium falciparum erythrocyte membrane protein 1 is a parasitized erythrocyte receptor for adherence to CD36, thrombospondin, and intercellular adhesion molecule 1. Proc Natl Acad Sci 93: 3497-3502.

Basu A, Tang H, Zhu X, Gu CC, Hanis C, Boerwinkle E, Risch N. 2008. Genome-wide distribution of ancestry in Mexican Americans. Hum Genet 124: 207-214.

Blumberg BS, Hesser JE. 1971. Loci differentially affected by selection in two American black populations. Proc Natl Acad Sci 68: 2554-2558.

Bryc K, Auton A, Nelson MR, Oksenberg JR, Hauser SL, Williams S, Froment A, Bodo J-M, Wambebe C, Tishkoff SA, et al. 2010. Genome-wide patterns of population structure and admixture in West Africans and African Americans. Proc Natl Acad Sci 107: 786-791.

Cui Y, Tian M, Zong M, Teng M, Chen Y, Lu J, Jiang J, Liu X, Han J. 2009. Proteomic analysis of pancreatic ductal adenocarcinoma compared with normal adjacent pancreatic tissue and pancreatic benign cystadenoma. Pancreatology 9: 89-98.

Davila S, Froeling FE, Tan A, Bonnard C, Boland GJ, Snippe H, Hibberd ML, Seielstad M. 2010. New genetic associations detected in a host response study to hepatitis B vaccine. Genes Immun 11: 232-238.

Erdman LK, Cosio G, Helmers AJ, Gowda D, Grinstein S, Kain KC. 2009. CD36 and TLR interactions in inflammation and phagocytosis: Implications for malaria. J Immunol 183: 6452-6459.

Esselens C, Malapeira J, Colome N, Casal C, Rodriguez-Manzaneque JC, Canals F, Arribas J. 2010. The cleavage of semaphorin 3C induced by ADAMTS1 promotes cell migration. J Biol Chem 285: 2463-2473.

Falush D, Stephens M, Pritchard JK. 2003. Inference of population structure using multilocus genotype data: Linked loci and correlated allele frequencies. Genetics 164: 1567-1587.

Freedman ML, Haiman CA, Patterson N, McDonald GJ, Tandon A, Waliszewska A, Penney K, Steen RG, Ardlie K, John EM, et al. 2006. Admixture mapping identifies $8 \mathrm{q} 24$ as a prostate cancer risk locus in African-American men. Proc Natl Acad Sci 103: 14068-14073.

Fry AE, Ghansa A, Small KS, Palma A, Auburn S, Diakite M, Green A, Campino S, Teo YY, Clark TG, et al. 2009. Positive selection of a CD36 nonsense variant in sub-Saharan Africa, but no association with severe malaria phenotypes. Hum Mol Genet 18: 2683-2692.

Garrigan D, Hedrick PW. 2003. Perspective: Detecting adaptive molecular polymorphism: Lessons from the MHC. Evolution 57: 1707-1722.

Goran MI. 2008. Ethnic-specific pathways to obesity-related disease: The Hispanic vs. African-American paradox. Obesity (Silver Spring) 16: 25612565.

Hancock AM, Witonsky DB, Gordon AS, Eshel G, Pritchard JK, Coop G, Di Rienzo A. 2008. Adaptations to climate in candidate genes for common metabolic disorders. PLoS Genet 4: e32. doi: 10.1371/ journal.pgen.0040032.

Ihaka R, Gentleman R. 1996. R: A language for data analysis and graphics. J Comput Graph Statist 5: 299-314.

The International HapMap Consortium. 2007. A second generation human haplotype map of over 3.1 million SNPs. Nature 449: 851-861.

Jemal A, Siegel R, Ward E, Murray T, Xu J, Smigal C, Thun MJ. 2006. Cancer statistics, 2006. CA Cancer J Clin 56: 106-130.

Kao WH, Klag MJ, Meoni LA, Reich D, Berthier-Schaad Y, Li M, Coresh J, Patterson N, Tandon A, Powe NR, et al. 2008. MYH9 is associated with nondiabetic end-stage renal disease in African Americans. Nat Genet 40: 1185-1192.

Kimura M. 2003. The neutral theory of molecular evolution. Cambridge University Press, Cambridge.

Kresse SH, Ohnstad HO, Paulsen EB, Bjerkehagen B, Szuhai K, Serra M, Schaefer KL, Myklebost O, Meza-Zepeda LA. 2009. LSAMP, a novel

\section{Genome Research}


candidate tumor suppressor gene in human osteosarcomas, identified by array comparative genomic hybridization. Genes Chromosomes Cancer 48: 679-693.

Kwiatkowski D. 1999. The molecular genetic approach to malarial pathogenesis and immunity. Parassitologia 41: 233-240.

Kwiatkowski DP. 2005. How malaria has affected the human genome and what human genetics can teach us about malaria. Am J Hum Genet 77: 171-192.

Li JZ, Absher DM, Tang H, Southwick AM, Casto AM, Ramachandran S, Cann HM, Barsh GS, Feldman M, Cavalli-Sforza LL, et al. 2008. Worldwide human relationships inferred from genome-wide patterns of variation. Science 319: 1100-1104

Li Y, Dinwiddie DL, Harrod KS, Jiang Y, Kim KC. 2010. Anti-inflammatory effect of MUC1 during respiratory syncytial virus infection of lung epithelial cells in vitro. Am J Physiol Lung Cell Mol Physiol 298: L558-L563.

Long JC. 1991. The genetic structure of admixed populations. Genetics 127: 417-428.

Matsuo K, Tajima K, Suzuki T, Kawase T, Watanabe M, Shitara K, Misawa K, Ito S, Sawaki A, Muro K, et al. 2009. Association of prostate stem cell antigen gene polymorphisms with the risk of stomach cancer in Japanese. Int J Cancer 125: 1961-1964.

McAllister CS, Toth AM, Zhang P, Devaux P, Cattaneo R, Samuel CE. 2010. Mechanisms of protein kinase PKR-mediated amplification of beta interferon induction by $\mathrm{C}$ protein-deficient measles virus. J Virol 84: 380-386.

Meltzer M. 1993. Slavery: A world history. Da Capo Press, New York.

Nielsen R. 2005. Molecular signatures of natural selection. Annu Rev Genet 39: $197-218$.

Nielsen R, Hellmann I, Hubisz M, Bustamante C, Clark AG. 2007. Recent and ongoing selection in the human genome. Nat Rev Genet 8: 857-868.

Oleksyk TK, Smith MW, O'Brien SJ. 2010. Genome-wide scans for footprints of natural selection. Philos Trans R Soc Lond B Biol Sci 365: 185-205.

Omi K, Ohashi J, Patarapotikul J, Hananantachai H, Naka I, Looareesuwan S, Tokunaga K. 2002. Fc $\gamma$ receptor IIA and IIIB polymorphisms are associated with susceptibility to cerebral malaria. Parasitol Int 51: 361-366.

Omi K, Ohashi J, Patarapotikul J, Hananantachai H, Naka I, Looareesuwan S, Tokunaga K. 2003. CD36 polymorphism is associated with protection from cerebral malaria. Am J Hum Genet 72: 364-374.

Oquendo P, Hundt E, Lawler J, Seed B. 1989. CD36 directly mediates cytoadherence of Plasmodium falciparum parasitized erythrocytes. Cell 58: $95-101$.

Patterson N, Hattangadi N, Lane B, Lohmueller KE, Hafler DA, Oksenberg JR, Hauser SL, Smith MW, O'Brien SJ, Altshuler D, et al. 2004. Methods for high-density admixture mapping of disease genes. Am J Hum Genet 74: 979-1000.

Patterson N, Price AL, Reich D. 2006. Population structure and eigenanalysis. PLoS Genet 2: e190. doi: 10.1371/journal.pgen.0020190.

Pereira RM, Teixeira KL, Barreto-de-Souza V, Calegari-Silva TC, De-Melo LD, Soares DC, Bou-Habib DC, Silva AM, Saraiva EM, Lopes UG. 2010. Novel role for the double-stranded RNA-activated protein kinase PKR: Modulation of macrophage infection by the protozoan parasite Leishmania. FASEB J 24: 617-626.

Pfaff CL, Parra EJ, Bonilla C, Hiester K, McKeigue PM, Kamboh MI, Hutchinson RG, Ferrell RE, Boerwinkle E, Shriver MD. 2001. Population structure in admixed populations: Effect of admixture dynamics on the pattern of linkage disequilibrium. Am J Hum Genet 68: 198-207.

Platt OS, Brambilla DJ, Rosse WF, Milner PF, Castro O, Steinberg MH, Klug PP. 1994. Mortality in sickle cell disease. Life expectancy and risk factors for early death. N Engl J Med 330: 1639-1644.

Praml C, Schulz W, Claas A, Mollenhauer J, Poustka A, Ackermann R, Schwab M, Henrich KO. 2008. Genetic variation of Aflatoxin B1 aldehyde reductase genes (AFAR) in human tumour cells. Cancer Lett 272: $160-166$.

Price AL, Weale ME, Patterson N, Myers SR, Need AC, Shianna KV, Ge D, Rotter JI, Torres E, Taylor KD, et al. 2008. Long-range LD can confound genome scans in admixed populations. Am J Hum Genet 83: 132-135.

Price AL, Tandon A, Patterson N, Barnes KC, Rafaels N, Ruczinski I, Beaty TH, Mathias R, Reich D, Myers S. 2009. Sensitive detection of chromosomal segments of distinct ancestry in admixed populations. PLoS Genet 5: e1000519. doi: 10.1371/journal.pgen.1000519.

Pritchard JK, Stephens M, Donnelly P. 2000. Inference of population structure using multilocus genotype data. Genetics 155: 945-959.

Purcell S, Neale B, Todd-Brown K, Thomas L, Ferreira MAR, Bender D, Maller J, Sklar P, de Bakker PIW, Daly MJ, et al. 2007. PLINK: A tool set for wholegenome association and population-based linkage analyses. Am J Hum Genet 81: $559-575$.

Reed TE. 1969. Caucasian genes in American Negroes. Science 165: 762-768.

Reich D, Patterson N, De Jager PL, McDonald GJ, Waliszewska A, Tandon A, Lincoln RR, DeLoa C, Fruhan SA, Cabre P. 2005. A whole-genome admixture scan finds a candidate locus for multiple sclerosis susceptibility. Nat Genet 37: 1113-1118.
Sabeti PC, Varilly P, Fry B, Lohmueller J, Hostetter E, Cotsapas C, Xie X, Byrne EH, McCarroll SA, Gaudet R, et al. 2007. Genome-wide detection and characterization of positive selection in human populations. Nature 449: 913-918.

Sakamoto H, Yoshimura K, Saeki N, Katai H, Shimoda T, Matsuno Y, Saito D, Sugimura H, Tanioka F, Kato S, et al. 2008. Genetic variation in PSCA is associated with susceptibility to diffuse-type gastric cancer. Nat Genet 40: $730-740$

Sankararaman S, Kimmel G, Halperin E, Jordan MI. 2008a. On the inference of ancestries in admixed populations. Genome Res 18: 668-675.

Sankararaman S, Sridhar S, Kimmel G, Halperin E. 2008b. Estimating local ancestry in admixed populations. Am J Hum Genet 82: 290-303.

Smith MW, O'Brien SJ. 2005. Mapping by admixture linkage disequilibrium: Advances, limitations and guidelines. Nat Rev Genet 6: 623-632.

Smith MW, Patterson N, Lautenberger JA, Truelove AL, McDonald GJ, Waliszewska A, Kessing BD, Malasky MJ, Scafe C, Le E. 2004. A highdensity admixture map for disease gene discovery in African Americans. Am J Hum Genet 74: 1001-1013.

Stannard D. 1993. American Holocaust. Oxford University Press, Oxford.

Sundquist A, Fratkin E, Do CB, Batzoglou S. 2008. Effect of genetic divergence in identifying ancestral origin using HAPAA. Genome Res 18: 676-682.

Tang H, Peng J, Wang P, Risch NJ. 2005. Estimation of individual admixture: Analytical and study design considerations. Genet Epidemiol 28: 289-301.

Tang H, Coram M, Wang P, Zhu X, Risch N. 2006. Reconstructing genetic ancestry blocks in admixed individuals. Am J Hum Genet 79: 1-12.

Tang H, Choudhry S, Mei R, Morgan M, Rodriguez-Cintron W, Burchard EG, Risch NJ. 2007. Recent genetic selection in the ancestral admixture of Puerto Ricans. Am J Hum Genet 81: 626-633.

Thomas H. 1999. The slave trade. The story of the Atlantic slave trade: 14401870. Simon and Schuster, New York.

Thorisson GA, Smith AV, Krishnan L, Stein LD. 2005. The international HapMap project web site. Genome Res 15: 1592-1593.

Weir BS, Cockerham CC. 1984. Estimating F-statistics for the analysis of population structure. Evolution 38: 1358-1370.

Weir BS, Cardon LR, Anderson AD, Nielsen DM, Hill WG. 2005. Measures of human population structure show heterogeneity among genomic regions. Genome Res 15: 1468-1476.

Winichagoon P, Fucharoen S, Chen P, Wasi P. 2000. Genetic factors affecting clinical severity in $\beta$-thalassemia syndromes. J Pediatr Hematol Oncol 22: 573-580.

Wood ET, Stover DA, Slatkin M, Nachman MW, Hammer MF. 2005. The $\beta$-globin recombinational hotspot reduces the effects of strong selection around $\mathrm{HbC}$, a recently arisen mutation providing resistance to malaria. Am J Hum Genet 77: 637-642.

Workman PL, Blumberg BS, Cooper AJ. 1963. Selection, gene migration and polymorphic stability in a U. S. white and negro population. Am J Hum Genet 15: 429-437.

Wu X, Ye Y, Kiemeney LA, Sulem P, Rafnar T, Matullo G, Seminara D, Yoshida T, Saeki N, Andrew AS, et al. 2009. Genetic variation in the prostate stem cell antigen gene PSCA confers susceptibility to urinary bladder cancer. Nat Genet 41: 991-995.

$\mathrm{Xu} \mathrm{S,} \mathrm{Jin} \mathrm{L.} \mathrm{2008.} \mathrm{A} \mathrm{genome-wide} \mathrm{analysis} \mathrm{of} \mathrm{admixture} \mathrm{in} \mathrm{Uyghurs} \mathrm{and}$ a high-density admixture map for disease-gene discovery. Am J Hum Genet 83: 322-336.

Xu S, Huang W, Wang H, He Y, Wang Y, Wang Y, Qian J, Xiong M, Jin L. 2007. Dissecting linkage disequilibrium in African-American genomes: roles of markers and individuals. Mol Biol Evol 24: 2049-2058.

Xu S, Huang W, Qian J, Jin L. 2008. Analysis of genomic admixture in Uyghur and its implication in mapping strategy. Am J Hum Genet 82: 883-894.

Xu S, Jin W, Jin L. 2009. Haplotype-sharing analysis showing Uyghurs are unlikely genetic donors. Mol Biol Evol 26: 2197-2206.

Xu S, Gupta S, Jin L. 2010. PEAS V1.0: a package for elementary analysis of SNP data. Mol Ecol Resour 10: 1085-1088.

Yeager M, Chatterjee N, Ciampa J, Jacobs KB, Gonzalez-Bosquet J, Hayes RB, Kraft P, Wacholder S, Orr N, Berndt S, et al. 2009. Identification of a new prostate cancer susceptibility locus on chromosome 8q24. Nat Genet 41: 1055-1057.

Yen CC, Chen WM, Chen TH, Chen WY, Chen PC, Chiou HJ, Hung GY, Wu HT, Wei CJ, Shiau CY. 2009. Identification of chromosomal aberrations associated with disease progression and a novel 3q13.31 deletion involving LSAMP gene in osteosarcoma. Int J Oncol 35: 775-788.

Zakharia F, Basu A, Absher D, Assimes TL, Go AS, Hlatky MA, Iribarren C, Knowles JW, Li J, Narasimhan B, et al. 2009. Characterizing the admixed African ancestry of African Americans. Genome Biol 10: R141. doi: 10.1186/gb-2009-10-12-r141.

Received April 14, 2011; accepted in revised form November 9, 2011. 


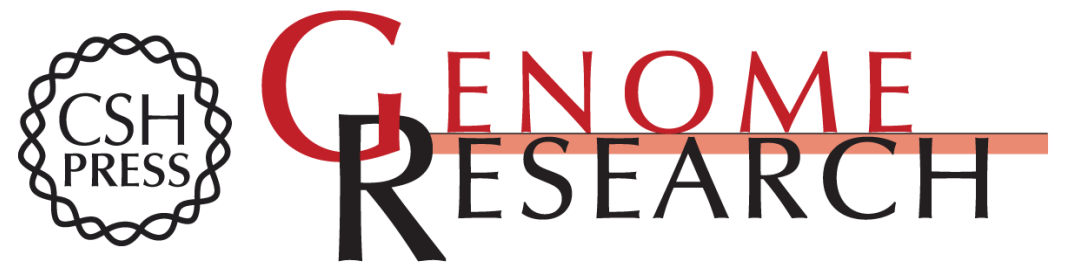

\section{Genome-wide detection of natural selection in African Americans pre- and post-admixture}

Wenfei Jin, Shuhua Xu, Haifeng Wang, et al.

Genome Res. 2012 22: 519-527 originally published online November 29, 2011

Access the most recent version at doi:10.1101/gr.124784.111

Supplemental Material

References

License

Email Alerting Service
http://genome.cshlp.org/content/suppl/2011/11/21/gr.124784.111.DC1

This article cites 78 articles, 16 of which can be accessed free at: http://genome.cshlp.org/content/22/3/519.full.html\#ref-list-1

Receive free email alerts when new articles cite this article - sign up in the box at the top right corner of the article or click here.

\section{Affordable, Accurate Sequencing.}

